Vol. 5 (1), pp. 001-010, January, 2015

ISSN: 2276-7797; ICV: 5.98

Copyright @2015, the copyright of this article is retained by the author(s)

DOI Link: http://doi.org/10.15580/GJMS.2015.1.051114379

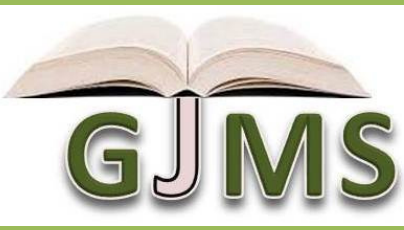

http://gjournals.org/GJMS

\title{
Is this Evidence of Success in Malaria Prevention and Control Measures?
}

\section{Prof. Omotayo O. Ebong ${ }^{1,2}$, Prof Chijioke A. Nwauche ${ }^{1,4}$, ljeoma H. Ogbuehi ${ }^{* 1,2}$, Dr Ifeyinwa N. Chijioke-Nwauche ${ }^{5}$, Dr Chinwe T. Ezirim ${ }^{3}$, Ruth E. Umoh ${ }^{1,4}$, Aniekan G. Afia ${ }^{1,4}$, Pius Zara-kokpa ${ }^{3}$}

${ }^{1}$ Centre for Malaria Research and Phytomedicine, University of Port Harcourt, Port Harcourt. ${ }^{2}$ Department of Pharmacology, Faculty of Basic Medical Sciences, University of Port Harcourt.

${ }^{3}$ Department of Health Services, Lulu Briggs Health Center, University of Port Harcourt.

${ }^{4}$ Department of Haematology and Blood Transfusion, Faculty of Clinical Sciences,

University of Port Harcourt Teaching Hospital.

${ }^{5}$ Department of Immunology and Infection, Faculty of Infectious and Tropical diseases, London School of Hygiene and Tropical Medicine, University of London.

Article No.: 051114379

Type: Research

DOI: 10.15580/GJMS.2015.1.051114379

Submitted: 05/11/2014

Accepted: $17 / 12 / 2014$

Published: 30/01/2015

*Corresponding Author

happyije@yahoo.com

E-mail: ljeoma H. Ogbuehi

Keywords:

Malaria Prevention, Anti-malarial,

Malaria Parasitaemia, Artemisinin
In Nigeria, mass distribution of Long Lasting Insecticide Treated Nets (LLINs), community awareness programs, increased availability of Artemisinin-based combination therapies (ACTs) and Biolarviciding have been part of strategies employed, with the aim of contributing to the realization of the sixth Millennium Development Goal - Combating Malaria. This study investigates malaria prevalence among adult subjects presenting for routine medical examination at the Lulu Briggs Health Centre, University of Port Harcourt. Blood samples of 354 willing subjects were tested for parasitemia using double microscopy and standard Rapid Diagnostic (RDT) Test Kits. Axillary temperature, genotype, blood group and packed cell volume of the subjects were also determined. Questionnaire was used to obtain information regarding their demographics, previous use of antimalarials, and malaria prevention strategies they have adopted. The results obtained on the prevalence of malaria were as follows; RDT, $7.4 \%$, double microscopy $11.0 \%$. Among the parasite-positive samples, $32(82.1 \%)$ were of AA, $6(15.4 \%)$ AS, and $1(2.5 \%)$ SS genotype, while on the other hand, 23 $(59 \%)$ were of $\mathrm{O}^{+}, 10(25 \%)$ of $\mathrm{A}^{+}, 3(8 \%)$ of $\mathrm{AB}^{+}$, and $3(8 \%)$ of the $\mathrm{B}^{+}$blood groups. The decline in malaria prevalence rate when compared to other studies, suggests that malaria control measures are having a degree of success and that individuals are making conscious effort to reduce mosquito bites. Also, the study reaffirms that microscopy still remains the gold standard in malaria diagnosis, even though RDTs are invaluable when immediate result is desired and where a laboratory is not in sight. 


\section{INTRODUCTION}

In recent years, malaria endemic nations with the support of the Roll Back Malaria Partnership (RBM) comprising of the World Health Organization (WHO), United Nations International Children Emergency Fund (UNICEF), United Nations Developmental (UNDP) and the World Bank, have develop multi-pronged strategies of malaria control and also deployed immense resources to realize their target of defeating malaria. There has been significant scalingup of malaria prevention and control measures in the last decade, including the widespread use of Insecticide treated nets (ITNs), Community awareness programs, Biolarviciding, Better diagnostics and the use of Artemisinin-based combination therapies (ACTs) (World Malaria Day Report 2013, Tambo et al., 2012). Evidence abounds proving that these efforts have been richly rewarded, as seen by the dwindling figures in malaria mortality rates. According to the World malaria report 2013, the WHO reported that malaria mortality rates have reduced since 2000 by more than $45 \%$ globally and by $49 \%$ in Africa (WHO 2013). Also, coverage of at-risk populations with malaria prevention and control measures was high in 2010 with a resultant decline in estimated malaria cases and deaths (WHO News Release, 2011). The statistics reveals that there were an estimated 655000 malaria deaths globally, in 2010, which is 36000 lower than the year before (WHO News Release, 2011). Long-lasting insecticidal nets have proved to be one of the least expensive but most effective weapon in the fight against malaria. The number of bed nets delivered to malaria-endemic countries in sub-Saharan Africa increased from 88.5 million in 2009 to 145 million in 2010 (WHO News Release, 2011; WHO Malaria Report, 2011). An estimated $50 \%$ of households in sub-Saharan Africa now have at least one bed net, and $96 \%$ of persons with access to a net, use it (WHO News Release, 2011). Furthermore, impressive efforts have been made in the availability of Rapid diagnostic testing kits so as to separate malaria from other febrile illnesses. The number of rapid diagnostic tests delivered by manufacturers climbed from 45 million in 2008 to 88 million in 2010, and the testing rate in the public sector in the WHO African Region rose from 20\% in 2005 to $45 \%$ in 2010 (WHO Malaria Report, 2011). Globally, the number of ACTs delivered to the public sector has also increased. In 2012, 331 million courses of artemisininbased combination therapies (ACTs) were procured as against 181 million in 2010, 158 million in 2009, and just 11 million in 2005 (WHO Malaria Report, 2012).

These decline in mortality figures and increases in availability of malaria control tools are impressive but the death rate due to malaria is still distressingly high for a disease that is entirely preventable and treatable. For example, malaria still kills a child every minute and it is still the leading cause of death among children under five (World Malaria Day Report 2013). Also, there is a growing concern that the current spate of drug and insecticide resistance is a threat to these frail gains in malaria control. Plasmodium falciparum resistance to artemisinins, which was confirmed on the CambodiaThailand border in 2009, has now also been identified at additional sites in Myanmar and Vietnam and even subSaharan Africa specifically Angola (Gueye et al., 2014; Van Hong et al., 2014). WHO has recommended that all countries ban the marketing of oral artemisinin-based monotherapies, which have been one of the major factors fostering the emergence and spread of anti malarial drug resistance (WHO Publication 2014; Bosman, 2010). Regardless of this, many countries including Nigeria, continues to allow the sale of these 'only-artemisinin' products maybe due to economic reasons (Bosman, 2010). The problem of mosquito resistance to insecticides also appears to be growing as 45 countries around the world have identified resistance to at least one of the four classes of insecticides used for malaria vector control; 27 of these are in sub-Saharan Africa (WHO News Release, 2011). Current malaria control efforts in Nigeria for example, are heavily reliant on a single class of insecticides, the pyrethroids, which are the most commonly used compounds for indoor residual spraying, and long-lasting insecticidal nets. Moreover, the projected shortfall in malaria funding may adversely affect the malaria control landscape, for example funding was reported to decrease slightly in 2013 from an annual subvention of US\$2.0 billion, and maybe drop further to an annual US $\$ 1.5$ billion by 2015 , (World Malaria Report, 2011) whereas millions of bed nets will need replacement in the coming years.

Despite these challenges, the Roll Back Malaria (RBM) Partnership have been revitalized by the gains of having eliminated malaria in the past 4 years, from countries including Morocco, Turkmenistan, and the United Arab Emirates (World Malaria Report, 2014). Thus, RBM has set new targets: to achieve near zero deaths by 2015 , and further elimination of the disease in an additional eight to ten countries.

Nigeria has more reported cases of malaria and deaths due to malaria than any other country in the world (Nigeria Malaria Fact Sheet, 2011). There are many projects inaugurated in the country to stem the tide of malaria burden, these include the President's Malaria Initiative (PMI), National Malaria Booster project and Malaria Control projects in the different states of the country. To this end, the countries has received support within and abroad, towards the development of evidence-based malaria policy through operations research, and achieving appropriate malaria diagnostics, case management and vector control.

Health promotion has been a key tool, usefully exploited in the Nigerian malaria control programme, it has been used to influence community behaviour towards the preventing and treatment components of malaria control strategies. Health seminars are usually organized regularly to encourage many communities to comply with instructions from spray operators during IRS 
campaigns and to take personal, protective measures against being bitten by malaria-infected mosquitoes. On the other hand, communities are also being taught to recognize the signs and symptoms of malaria and seek early treatment. Information, education and communication (IEC) messaging is delivered through channels such as community outreach events, radio talk shows e.t.c. For example, Rivers State, one of the states in the forefront of malaria control in Nigeria has been implementing Indoor Residual Spraying (IRS) coupled with focal larviciding for malaria vector control since the 2012. Large-scale larviciding using liquid pyrethrum and biolarviciding using strains of Bacillus sphaericus and Bacillus thuringiensis have been the employed in the malaria control programme of the state. Little wonder then that the malaria prevalence in children age 6 to 59 months in the South-South region is 32.2 percent, as compared to $50.3 \%$, in the South West region (Nigeria Malaria Fact Sheet, 2011). The state has at the present recorded $71.6 \%$ coverage of the population with LLIN and continues to provide free ACTs for use in the treatment of uncomplicated or even severe malaria for all age groups. In addition, the state has in partnership with the Economic Community of West African States (ECOWAS), concluded arrangements to commence the construction of a biolarvicide factory to control and eliminate malaria in the state and environs (NMCP Rivers State, M\&E Report).

In this study, we aimed at investigating the prevalence of malaria in adults, at the present time, given the malaria intervention projects in the recent past.

\section{MATERIALS AND METHODS}

\section{Study Area}

This study was conducted at the Lulu Briggs Health Centre, located at the University of Port Harcourt Teaching Hospital, Nigeria. Port Harcourt city is the capital of Rivers State, the heart of the Niger Delta region of Nigeria. Port Harcourt is an important merchant port and the center of Nigeria's oil and gas industry. The region consists of flat plains with a network of rivers, tributaries and creeks which favors breeding of mosquitoes. It features a tropical climate with low altitude, lengthy and heavy rains at its peak during the months of March to November and a nadir during the dry season months of December to February and, consequently a high malaria transmission rate throughout the year (Adejuwon et al., 2012; Salako, 2007). This study area was chosen because of its topography which resulted in malaria being one of the ten most common causes of morbidity in the region, more so the region has benefited from vigorous malaria intervention projects in the recent past.

\section{Study Design and Sample Size}

A cross-sectional survey was conducted among adults presenting for routine medical check-up at the Lulu Briggs Health Centre, University of Port Harcourt between September 2012 and March 2013. Systematic random sampling technique was used to obtain the subjects. Sample size determination was based on the Leslie-Kish formular (Araoye, 2004). Using a prevalence of $26 \%$ (Wogu et al., 2013), the sample size needed to achieve the desired precision of 0.05 at $95 \%$ confidence level was obtained from the equation:

$$
\frac{\text { Sample Size }(n)}{d^{2}}=Z^{2} P(1-P)
$$

$Z$ = Standard normal deviate corresponding to confidence interval.

Since we chose $95 \%$ C.I = Z value of 1.960

time

$\mathrm{p}=$ prevalence of malaria infection at a given (desired precision)

$\mathrm{d}=$ margin of sample error to be tolerated The calculated minimum sample size was 295.6 subjects.

\section{Blood Samples}

$1 \mathrm{ml}$ of blood was drawn from subjects using venipuncture technique (Okocha et al., 2005; Epidi et al., 2008). Soft tubing tourniquet was tied around the upper arm of the patient to enable the index finger feel a suitable vein. The puncture site was then cleansed with methylated spirit (methanol) and venepuncture made with the aid of a $21 \mathrm{G}$ needle attached to a $5 \mathrm{~mL}$ syringe. When sufficient blood had been collected, the tourniquet was released and the needle removed immediately while the blood was transferred into an EDTA bottle (Epidi et al., 2008).

Duplicate thick and thin blood film methods were made on clean, grease-free microscope slides and a drop of each blood sample was placed in the center of a clean glass slide. Thereafter, the reverse side of the slide was cleaned with cotton wool and kept for airdrying and staining with field's stain. The slide was held with the dried thick film side facing downward and dipped in field's stain A (eosin) for 5 secs. It was washed off gently in clean water and then dipped in field's stain B (methyl azure) for 5 secs and washed again in clean water. The back of the slide was cleaned with cotton wool and kept in the draining rack to air-dry for eventual examination under the microscope, using oil immersion at 100X magnification to observe for plasmodium parasites. Presence of ring forms of plasmodium and trophozoites of plasmodium indicate positive results.

Thin film was carried out following the examination of thick film to identify the particular species of the plasmodium responsible for the infection; it was stained with commercially prepared Leishman stain. Other materials used included a photo microscope, 
Field's stain A (A polychrome methylene blue, disodium hydrogen phosphate and potassium hydrogen phosphate) and Field's stain B (Eosin, disodium hydrogen phosphate and potassium hydrogen phosphate), EDTA (ethylene diamine tetra acetic acid) bottles, methylated spirit (methanol), cotton wool, tourniquet, syringes $(5 \mathrm{~mL})$ and needles $(21 \mathrm{G})$. The collected blood samples were analyzed within 1 to $2 \mathrm{~h}$ of collection. The number of parasites was counted against 200 leucocytes and quantification of parasite density was estimated by assuming 8,000 leucocytes/ $\mu$ l blood. Samples were considered negative when no parasite was detected after examining 100 microscopic fields (Mbuh et al., 2003).

The malaria microscopic examination was performed by two independent experienced microscopists, trained at Andi Centre of Excellence for malaria diagnosis, University of Lagos State for the interpretation of malaria blood slides and identification of the malaria parasite species. Also axillary temperature measurement was taken for all participants and recorded.

Concomitantly, blood samples were also analysed using CareStart Malaria HRP2/pLDH Pf Test kit manufactured by Access Bio, Inc., listed by the Global Fund Quality Assurance Policy and recommended by the WHO-FIND Malaria RDT Evaluation Programme (Global Fund, 2014; WHO RDT Test Performance Result). CareStart Malaria HRP2/pLDH Pf Test targets the $P$. falciparum specific antigen histidine-rich protein (HRP-2) and the pan-Plasmodium antigen lactate dehydrogenase (pLDH). Plasmodium Lactate Dehydrogenase enzyme (PLDH) is a $33 \mathrm{kDa}$ oxidoreductase and the last enzyme of the glycolytic pathway essential for ATP generation and one of the most abundant enzymes expressed by $P$. falciparum (Howard et al., 1986; Maltha et al., 2010). The overall sensitivity for the detection of $P$. falciparum by the test kit is $88.8 \%$, increasing to $94.3 \%$ and $99.3 \%$ at parasite densities above 100 and 1,000/ $\mu$ l respectively (Xiaodong et al., 2013). The test kits were stored as recommended, quality controlled and the validity of the particular batch purchased was certified before usage. $0.5 \mathrm{ml}$ of whole blood of the patient is mixed with the diluents and dropped into the well of the cassette. The red blood cells are lysed by the diluents, releasing the malaria parasite antigens, which react with the antibody that was embedded on the well. A positive result gives two colored lines (for test and control); while a negative result gives a colored line. The result is read after 15-30 minutes of commencement of the procedure. Tests were performed according to manufacturer's instructions. Readings were carried out at daylight, assisted by a standard electric bulb, by three malaria lab technicians. The first observer performed readings at 20 minutes, reading time recommended by the manufacturer, followed by observers 2 and 3 within the next 10 minutes. The observers were blinded to each other's readings and to the results of microscopy. In the case when no control line appeared, the test was considered invalid and was repeated.

\section{Socio-Demographic and Malaria Prevention Data}

A semi-structured and pre-tested questionnaire was administered to extract information about the sociodemographics, date of last antimalarial medication taken and malaria prevention strategies employed by the subject.

\section{Statistical Analysis}

Data were compiled, coded and analyzed using Statistical Package for Social Science (SPSS) software version 17. Frequencies and means with standard error of mean were generated to quantify the variables. Chi square was used to determine correlation between variables, and $\mathrm{P}$-value set at 0.05 significant level.

\section{Ethical Clearance}

Ethical clearance was obtained from the Ethical Committee of the University of Port Harcourt Teaching Hospital. All adults who participated in the study signed an informed consent form to affirm their willingness to participate in the study. Respondents were free to withdraw from the study at any stage without the fear of reprisal.

\section{RESULTS}

A total of 354 subjects residing in different communities and locations all from Rivers State were enrolled in the study. The demographics and clinical characteristics of the subjects are presented in table 1.

\section{Parasitemia detection using microscopy and RDT:}

As shown in table 1, there were no samples in which a parasitemia was seen with RDT, but could not be confirmed by microscopy. On the other hand, $6.2 \%$ of samples tested parasite positive with microscopy but not with RDT, whereas $4.8 \%$ of the samples tested parasite positive with RDT and was confirmed with. The frequencies and distribution of malaria parasite according to gender, genotype, and blood group are summarized in tables 2, 3 and 4.

\section{Antimalarial usage prior to the study:}

The questionnaire obtained information from the subjects on the last time they took an antimalarial medication, prior to the study. The responses are summarized in table 4. Also the distribution of the frequency of antimalarial usage prior to the study, correlated with presence of parasitemia is as shown in figure 1. 


\section{Type of antimalarial taken}

Out of the 354 subjects interviewed using the questionnaire, $22 \%$ had taken an antimalarial two weeks prior to the study. The type of drug taken is illustrated thus (Figure 2):

\section{Method of malaria prevention employed}

Data on the method of malaria prevention methods employed by the subjects is illustrated in figure 3 below.

Table 1: Demographics and Clinical Characteristics of Subjects

\begin{tabular}{|c|c|}
\hline Characteristics & n (354) \\
\hline \multicolumn{2}{|l|}{ Sex Ratio } \\
\hline Male & $173(48.9 \%)$ \\
\hline Female & $181(51.1 \%)$ \\
\hline \multicolumn{2}{|l|}{ Age (years) } \\
\hline $10-20$ & $63(17.8 \%)$ \\
\hline $21-30$ & $192(54.2 \%)$ \\
\hline $31-40$ & $88(24.9 \%)$ \\
\hline $41-50$ & $11(3.1 \%)$ \\
\hline Mean age \pm SD & $27.2 \pm 2.1$ \\
\hline Range & $17 y r s-42 y r s$ \\
\hline \multicolumn{2}{|l|}{ Weight (kg) } \\
\hline Mean Weight \pm SD & $62.7 \pm 4.3$ \\
\hline Range & $54-82$ \\
\hline \multicolumn{2}{|l|}{$\%$ Axillary temp. $\left({ }^{\circ} \mathrm{C}\right)$} \\
\hline$<37.5^{\circ} \mathrm{C}$ & $329(93 \%)$ \\
\hline$>37.5^{\circ} \mathrm{C}$ & $25(7 \%)$ \\
\hline Mean axillary temp. $\left({ }^{\circ} \mathrm{C}\right)$ & $38.3 \pm 0.55$ \\
\hline \multicolumn{2}{|l|}{ Genotype } \\
\hline AA & $164(46.3 \%)$ \\
\hline AS & $183(51.7 \%)$ \\
\hline SS & $7(2 \%)$ \\
\hline \multicolumn{2}{|l|}{ Blood Group } \\
\hline $\mathrm{A}^{+}$ & $10(25 \%)$ \\
\hline $\mathrm{B}^{+}$ & $3(8 \%)$ \\
\hline $\mathrm{O}^{+}$ & $23(59 \%)$ \\
\hline $\mathrm{AB}^{+}$ & $3(8 \%)$ \\
\hline \multicolumn{2}{|l|}{ \% Levels of positive parasitemia } \\
\hline \% Parasite positive by Microscopy alone but not RDT & $22(6.2 \%)$ \\
\hline \% Parasite positive by RDT \& confirmed by microscopy & $17(4.8 \%)$ \\
\hline \% Parasite positive by RDT alone but not microscopy & $0(0 \%)$ \\
\hline$\%$ total parasitemia detected by both methods & $39(11.0 \%)$ \\
\hline
\end{tabular}

Table 2: Frequency and distribution of parasitemia according to gender

\begin{tabular}{|l|l|l|l|}
\hline Sex & No Tested (\%) & No. positive (\%) & No. negative (\%) \\
\hline Males & $173(48.9)$ & $23(6.5)$ & $150(42.4)$ \\
\hline Females & $181(51.1)$ & $16(4.5)$ & $165(46.6)$ \\
\hline Total & $354(100.0)$ & $39(11.0)$ & $315(89.0)$ \\
\hline
\end{tabular}

Table 3: Frequency and distribution of parasitemia according to genotype

\begin{tabular}{|l|l|l|l|}
\hline Genotype & No Tested (\%) & No. positive (\%) & No. negative (\%) \\
\hline AA & $164(46.3 \%)$ & $32(82.1 \%)$ & $132(37.3 \%)$ \\
\hline AS & $183(51.7 \%)$ & $6(15.4 \%)$ & $177(50.0 \%)$ \\
\hline SS & $7(2 \%)$ & $1(2.5 \%)$ & $6(1.7 \%)$ \\
\hline Total & $354(100.0 \%)$ & $39(11 \%)$ & $315(89.0 \%)$ \\
\hline
\end{tabular}


Table 4: Frequency of antimalarial usage prior to the study, correlated with sex ratio

\begin{tabular}{|l|l|l|}
\hline Sex & $\begin{array}{l}\text { Have taken antimalarial in the past 2 } \\
\text { weeks (\%) }\end{array}$ & $\begin{array}{l}\text { Have not taken antimalarial in } \\
\text { the past 2 weeks (\%) }\end{array}$ \\
\hline Males & $31(8.8)$ & $142(40.1)$ \\
\hline Females & $47(13.3)$ & $134(37.9)$ \\
\hline Total & $78(22.0)$ & $276(78.0)$ \\
\hline
\end{tabular}

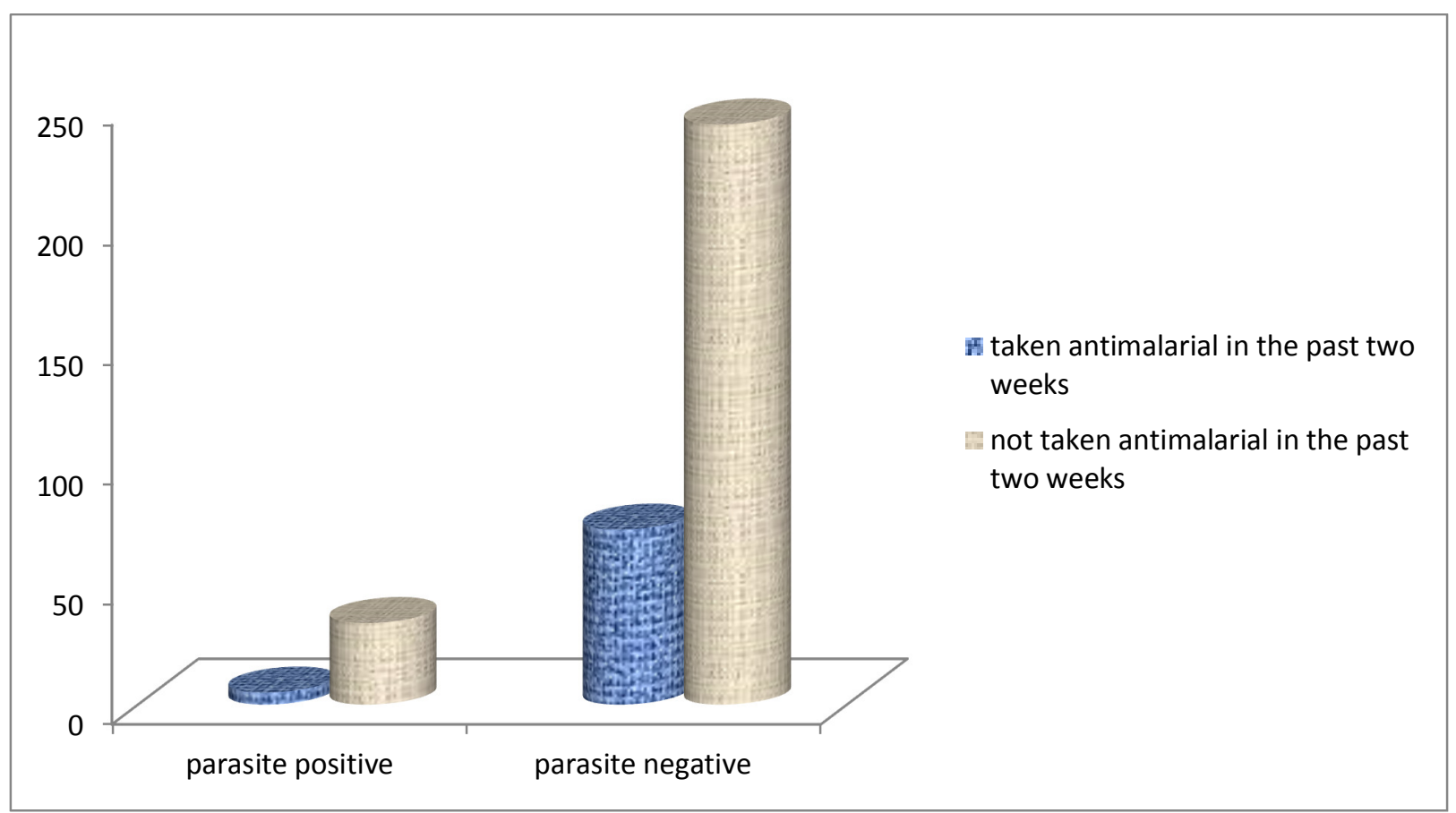

Figure 1: Frequency of antimalarial usage prior to the study, correlated with parasitemia 


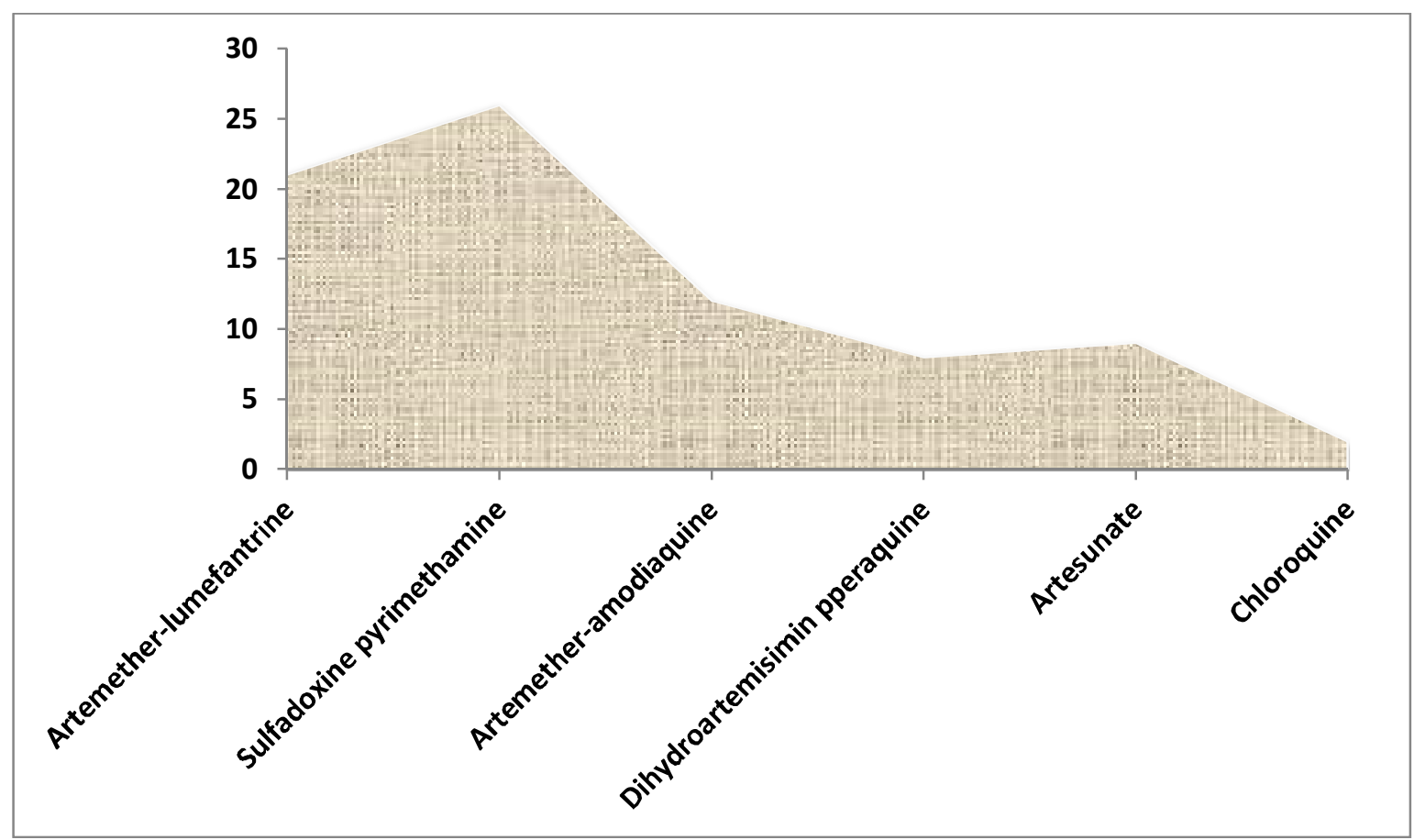

Figure 2: Type of antimalarial taken

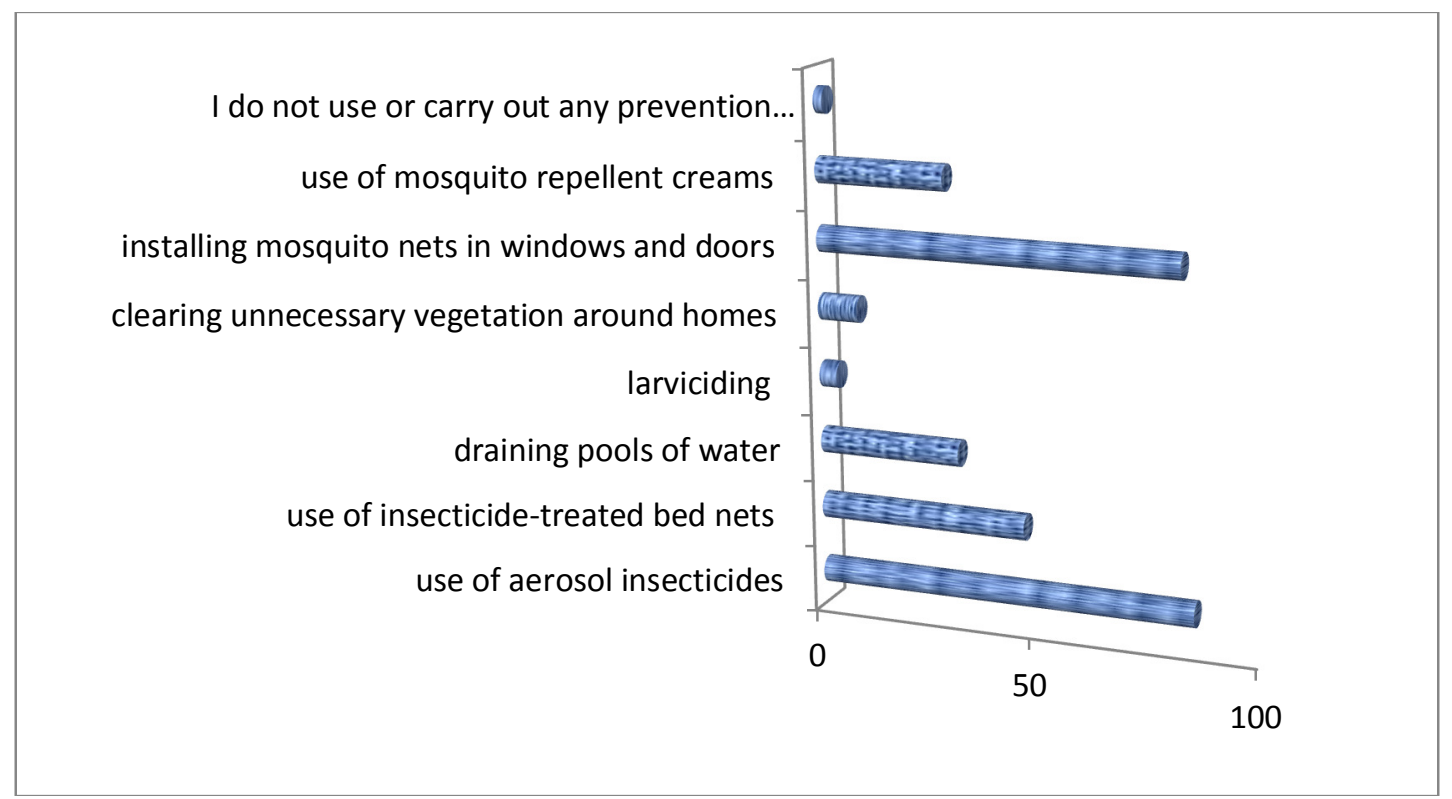

Figure 3: Method of malaria prevention employed

\section{DISCUSSION AND CONCLUSION}

In this study, we observed a malaria parasite prevalence of $6.2 \%$ by microscopy and of $4.8 \%$ by RDT. These figures are lower than the prevalence of $12.56 \%$ reported in another city in the Niger Delta Region (Pondei et al., 2012) and that of a recent study in Port Harcourt, wherein the overall prevalence among pregnant women was 26\% (Wogu et al., 2013). Other studies among HIV Infected Patients at the University of
Port Harcourt Teaching Hospital and blood donors at the Lagos University Teaching Hospital, Lagos, Nigeria reported $26.5 \%$ prevalence respectively (Wariso et al., 2011; Agboola et al., 2010). However, our results are similar to that of Adeoye et al, 2011, who reported a prevalence of $10.1 \%$ among blood donors in Lagos State and $9.6 \%$ prevalence of congenital malaria among newborns in Port Harcourt, Nigeria (George et al., 2013).

With regards to the influence of blood group type on susceptibility to malaria infection, earlier studies claim 
that Blood group $O$ protects against $P$. falciparum malaria Cserti et al .,2007; Rowe et al., 2007 and Akhigbe et al., 2011). Whereas our results showed a higher incidence of malaria parasitaemia among the blood group $O$ Rhesus $D$ positive subjects. Our findings though, agree with several other studies (Otajevwo., 1997; Akenji., 2004 and Otajevwo., 2013) that did not observe any significant association of ABO blood group to susceptibility to malaria infection in their studies. However, our result may also be attributed to the fact that $59 \%$ of the subjects tested, were of $O$ Rhesus positive blood group.

The incidence of malaria parasitaemia was predominant among the AA genotype subjects (42.3\%) than the AS (32.5\%) and SS (40\%). This is not surprising as several scientific articles corroborates this finding, (Aidoo et al., 2002; Tekola et al., 2008 and Yahaya et al., 2013) highlighting that the sickle cell traits (HbAS) confers higher resistance to severe and complicated malaria attack because of the recessive gene present.

Microscopy still remains the gold standard for the determination of malaria parasitemia level, however RDTs are invaluable in areas with no equipped medical laboratories and for immediate diagnosis and treatment, (Sheyin et al., 2013). In our study, as well as other studies the sensitivity of the CARE START RDT to $P$. Falciparum was found to be lower than that of microscopy as there were $1.4 \%$ of parasitemia that were undetected by the RDT (Xiaodong et al., 2013). Sheyin et al., reported that the sensitivity of the CareStart ${ }^{\mathrm{TM}}$ RDT was $78.4 \%$.

More females than males were seen to have taken an antimalarial two weeks prior to our study, this may also due to the fact that more women were surveyed than men. Commendably, many respondents install door and window nets and also use aerosol insecticides to reduce their exposure to mosquito bites. Also, most of the respondents took sulfadoxinepyrimethamine and Artemether/ Lumefantrine. However, it is sad that some still use artesunate and Chloroquine in the treatment of malaria regardless the injunction for the discontinuance of monotherapies. The government thus needs to implement these policies by banning the importation or local manufacturing of these drugs, in view of the threatening parasite resistance to Artemisinin.

Although currently malaria is caused by five different species of the Plasmodium, $P$. falciparum was the only malaria parasite species encountered in this study. This is because in Nigeria, $98 \%$ of all cases of malaria is due to $P$. falciparum (NMCP - Lagos State Report). The population of subjects surveyed can rightly be describes as asymptomatic, as only $7 \%$ were febrile $\left(>37.5^{\circ} \mathrm{C}\right.$ ), it also indicates that only a slightly low percentage of the apparently healthy persons studied, were infested by malaria with Plasmodium. Majority of the subjects live in the urban areas of Port Harcourt and they were mostly educated with or above the secondary school cadre. These factors in addition to the high saturation level of malaria control interventions may have contributed to the reduction in the prevalence rate.

The efforts put into malaria control in Nigeria should be lauded, nonetheless, it will be more rewarding if future malaria interventions is directed toward elimination of malaria involving enhanced surveillance with effective case management, focused larval control, and behavior change communication.

\section{ACKNOWLEDGEMENT}

This study is partly supported by WHO STEP B project, and we appreciate their financial and infrastructural support towards the upgrade of our Malaria Laboratory. The authors also acknowledge the contributions of $\mathrm{Dr}$ K.C Anugweje, Medical Director of Lulu Briggs Health Center, Mrs Ifeoma Opurum of the Medical Records Department, Lulu Briggs Health Center and all staff of Centre for Malaria Research and Phytomedicine, University of Port Harcourt, Nigeria.

\section{REFERENCES}

Invest in the Future: Defeat Malaria. World Malaria Day (2013) - Focus on Africa. A Publication by the Statistics and Monitoring Section, Division of Policy and Strategy in Collaboration with Health Section, Programme Division at UNICEF New York.

www.unicef.org/health/files/malaria brochure 18 april2013.pdf

Tambo E, Adedeji AA, Huang F, Chen J, Zhou S, and Tang L. (2012). Scaling Up Impact of Malaria Control Programmes: A Tale of Events in SubSaharan Africa and People's Republic of China. Infect Dis Poverty; 1: 7. Doi: 10.1186/20499957-1-7

WHO - Media Centre - World Malaria Report (2013) http://www.who.int/mediacentre/news/releases/2 013/World-Malaria-Report-20131211/En/

WHO News Release (2011). Media Centre - Malaria Deaths are down but Progress Remains Fragile. http://www.who.int/mediacentre/news/releases/2 011/Malaria Report 20111213/En/

World Malaria Report (2011). Fact Sheet http://www.who.int/malaria/world malaria report 2011/wmr2011 factsheet.pdf

World Health Organization (2012). Test Treat and Track. Scaling Up Diagnostic Testing, Treatment and Surveillance for Malaria. www.who.int/malaria/publications/atoz/test_treat_ track_brochure.pdf

Gueye C.S, Newby G, Hwang J, Phillips AA, Whittaker M, Macarthur JR, Gosling RD and Feachem R. (2014) The Challenge of Artemisinin Resistance Can Only Be Met by Eliminating Plasmodium Falciparum Malaria Across the 
Greater Mekong Subregion. Malaria Journal 2014, 13:286. http://www.malariajournal.com/content/pdf/14752875-13-286.pdf

Van Hong N, Amambua-Ngwa A, Tuan NQ, Cuong DD, Giang NT, Van Dung N, Tinh TT, Van Tien $\mathrm{N}$, Phuc BQ, Duong TT, Rosanas-Urgell A, D'alessandro U, Van Geertruyden J-P, Erhart A. (2014) Severe Malaria Not Responsive To Artemisinin Derivatives In Man Returning From Angola To Vietnam. Emerg Infect Dis, 20. doi:10.3201/Eid2007.140155.

WHO Global Malaria Programme Publication (2014). Withdrawal of Oral Artemisinin-Based

Monotherapies.

http://www.who.int/malaria/publications/atoz/oralartemisinin-based-monotherapies-1 may2014.pdf

Bosman A. (2010). Threat of Oral ArteMonotherapies. WHO Global Malaria Programme. Artemisinin Conference, Antananarivo, Madagascar.

World Malaria Report (2011). Chapter 3 - Financing Malaria Control. http://www.who.int/malaria/world_malaria_report_ 2011/wmr2011_chapter3.pdf

WHO Malaria Report 2014. Elimination Case Studies.

http://www.who.int/malaria/areas/elimination/case studies/en/

Nigeria Malaria Fact Sheet (2011). United States Embassy in Nigeria. http://photos.state.gov/libraries/nigeria/231771/publi c/december-malariafactsheet2.pdf. Economic Section, United States Embassy in Nigeria.

River State Malaria Control Programme: Monitoring and Evaluation Report (2012).

Adejuwon JO. (2012). Rainfall Seasonality In The Niger Delta Belt, Nigeria. Journal of Geography and Regional Planning. Vol. 5(2), Pp. 51-60, 18.

Salako FK. (2007) Temporal Variation of Rainfall Erosivity In Southern Nigeria. Asset Series A; 2007; 7 (1): 190-202 Asset.

Araoye MO. (2004) Research Methodology with Statistics for Health and Social Sciences. Ilorin, Nigeria: Nathadex Publishers; P.118 - 119.

Wogu MN, Nduka FO and Wogu MD. (2013). Prevalence of Malaria Parasite Infection among Pregnant Women Attending Antenatal Clinics in Port Harcourt, Rivers State, Nigeria. International Journal of Tropical Disease \& Health 3(2): 126-132.

Okocha CE, Ibeh CC, Ele PU and Ibeh NC. (2005). The Prevalence of Malaria Parasitaemia in Blood Donors in a Nigerian Teaching Hospital. Journal of Vector Borne Diseases 142, 21-24.

Epidi TT, Nwani CD and Ugorji NP. (2008). Prevalence of Malaria in Blood Donors in Abakaliki Metropolis, Nigeria. Scientific Research and Essay 3, 162-164.

Mbuh FA, Galadima M and Ogbadu L. (2003) Rate of Co-Infection with Malaria Parasites and Salmonella
Typhi in Zaria, Kaduna state, Nigeria. Annals of African Medicine. 2003; 2(2):6-7

Global Fund to Fight Aids, Tuberculosis and Malaria. Version 9, 2014. List of Rapid Diagnostic Test (RDT) Kits For Malaria Classified According To The Global Fund Quality Assurance. Policy http://www.theglobalfund.org/en/procurement/quality /diagnostics/

Malaria Rapid Diagnostic Tests Accepted Into Round 2 of Product Testing at US Centers for Disease Control and Prevention (CDC). http://www.wpro.who.int/malaria/nr/rdonlyres/784ae9 a9-4f5a-4216-93fc-

f9fab12a2c0c/0/prodtestrnd2summarylist.pdf

Howard RJ, Makler MT, Deressa W, et al. (1986) Secretion of Malaria Histidine Rich Protein 11 (Pf Hrp 11) from Plasmodium Infected Erythrocyte. Journal of Cell Biology, 1986;103: 1269-1277.

Maltha J, Gillet P, Bottieau E, Cnops L,Van Esbroeck M and Jacobs J. (2010). Evaluation of a Rapid Diagnostic Test (Carestart ${ }^{\mathrm{TM}}$ ) Malaria Hrp-2/PIdh (Pf/Pan) Combo Test) for the Diagnosis of Malaria in a Reference Setting. Malaria Journal 2010, 9:17. http://www.malariajournal.com/content/9/1/171.

Xiaodong S, Tambo E, Chun W, Zhibin C, Yan D, Jian W, Jiazhi W and Xiaonong Z. (2013). Diagnostic Performance of Carestart TM Malaria Hrp2/Pldh (Pf/Pan) Combo Test Versus Standard Microscopy on Falciparum and Vivax Malaria Between ChinaMyanmar Endemic Borders. Malaria Journal 2013, 12:6 Doi:10.1186/1475-2875-12-6. http://www.malariajournal.com/content/12/1/6

Pondei K, Lawani L and Ndiok E. (2012). The Malaria Parasite in Screened Blood in a Tertiary Health Centre in the Malaria-Endemic Niger Delta Region of Nigeria. Global Advanced Research Journal of Microbiology (Issn: 2315-5116) Vol. 1(11) Pp. 188193.

Wariso KT and Nwauche CA. (2011). The Prevalence of Malaria Antigen In The Serum of HIV Seropositive Patients In Port Harcourt. The Nigerian Health Journal, Vol. 11, No 4, October - December, 2011.

Agboola TF, Ajayi MB, Adeleke MA and Gyang PV (2010). Prevalence of Malaria Parasite among Blood Donors in Lagos University Teaching Hospital, Lagos Nigeria. Annals of Biological Research, 2010, $1 \quad$ (3): $\quad 72-75$ (http://scholarsresearchlibrary.com/archive.html).

Adeoye GO and Ogbonnaya CO (2011). Relationship of Malaria to HBV and HIV Status among Blood Donors in Lagos State. Nigerian Journal of Parasitology; 32(1): 71-77.

George IO, Jeremiah I and Kasso T. (2013) Prevalence of Congenital Malaria In Port Harcourt, Nigeria. British Journal of Medicine and Medical Research 3(2): 398-406, 2013.

Cserti CM and Dzik WH (2007). The ABO blood group system and Plasmodium falciparum malaria. Blood: 110

(7)

2007. 
http://www.bloodjournal.org/content/110/7/2250?sso -checked $=1$

Rowe JA, Handel IG, Thera MA, Deans A, Lyke KE, Koné $A$ et al., 2007. Blood group $O$ protects against severe Plasmodium falciparum malaria through the mechanism of reduced resetting. Proceedings of the National Academy of Sciences of the United States of America. vol. 104 no. 44. 17471-17476, doi: $\quad$ 10.1073/pnas.0705390104. http://www.pnas.org/content/104/44/17471.long

Akhigbe RE, Ige SF, Adegunlola GJ, Adewumi MO, Azeez MO (2011). Malaria, Haemoglobin Genotypes and ABO Blood Groups in Ogbomoso, Nigeria. Inter. J. Trop. Med. 6(4): 73-76.

Otajevwo FD. (1997) ABO Blood groups Association with Malaria Parasitaemia among residents in Warri, Delta State. Warri Journal of Science and Technology. 1997; 4(1):32-35.

Akenji N, Wepngong P, Jane FA. (2004) Effects of ABO Rh blood groups, G-6-P-D enzyme acuity and hemoglobin genotypes on malaria parasitaemia and parasite density. Afr J Health Science. 2004;11:9397.

F. D. Otajevwo. Prevalence of Malaria Parasitaemia and Its Association with ABO Blood Grouping among Students of Igbinedion University Okada, Nigeria. British Journal of Medicine and Medical Research 3(4): 1164-1177, 2013
Yahaya O, Umar IO, Dashen MM, Oyinloye SO, Yabefa JA, and Okwunjo OC. (2013) Malaria Parasitaemia among Different Genotypic Groups in Idah Metropolis, Kogi State, Nigeria Journal of Medical and Applied Biosciences Volume 5, Number 1, 2013.

Aidoo M, Terlouw DJ, Kolczak MS and Mcelroy PD (2002). Protective Effect of the Sickle-Cell Gene against Malaria Morbidity and Mortality. Lancet 359:1311-1312.

Endeshaw T, Gebre T, Ngondi J, Graves PM, Shargie EB, Ejigsemahu Y, Ayele B, Yohannes G, Teferi T et al. (2008) Evaluation of Light Microscopy and Rapid Diagnostic Test for the Detection of Malaria under Operational Field Conditions: A Household Survey In Ethiopia. Malaria Journal 2008, 7:118. http://www.malariajournal.com/content/7/1/118.

Sheyin Z1 and Bigwan IE (2013). Comparison of Care Start Hrp2 Rapid Malaria Test with Light Microscopy for Guiding Patient's Treatment of Fever in Nigerian Endemic Area. Journal of Medicine and Medical Sciences Vol. 4(9) Pp. 353-356, September 2013 doi: http:/dx.doi.org/10.14303/jmms.2013.109

Lagos State Ministry of Health - Malaria Control Programme. $\quad 1.1 \quad$ Introduction. http://www.lagosstateministryofhealth.com/program me_info.php?programme_id=6. 